\title{
Review of Tony Lawson's Essays on the nature and state of modern economics. London: Routledge, 2015, 262 pp.
}

\author{
MARCO SEBASTIANELLI \\ Institute for Advanced Study of Pavia
}

The book by Tony Lawson entitled Essays on the nature and state of modern economics comes at a particularly fitting time in the history of the economic academic discipline. After what has been regarded by many as one of its major setbacks-namely the failure to predict the 2008 global financial crisis-economics has been severely shaken, marginally challenged, but ultimately left untouched by the debates on its conditions that have sparked in the last few years. Therefore, Lawson's choice to assemble a number of previously published papers and a new one into this collection constitutes an important and welcome contribution to the methodology and philosophy of economics literature.

The point of departure for Lawson's book is the idea that modern economics lies in a state of intellectual disarray due to the detachment from social reality, its lack of explanatory and predictive successes, and more generally the absence of a sense of direction. The unhealthy state of the discipline, Lawson notes in the introductory chapter, has been recognised by both heterodox and mainstream contributors, but despite this bipartisan acknowledgement, criticisms and discussions have been mostly superficial and unable to steer the course of economics back onto its tracks. Lawson's collection of papers tackles precisely this issue: it is aimed primarily at filling the gaps in our understanding of the contemporary history of economic thought, including the reasons behind its recent failures, and secondly at evaluating possible alternatives to the contemporary mainstream paradigm.

As Mark Blaug (cited in Lawson 2015, 174) bluntly and concisely put it in a passage cited multiple times by Lawson, "modern economics is sick". According to the author, the causes of economics' bad state should not be located in recent events and theoretical developments. Instead, it emerged decades ago as the culmination of a process that originated in the past century with the growing mathematisation of the discipline. Therefore, we should not give in to the temptation to 
consider the failure to predict a single episode (i.e., the recent global financial crisis) as the proof that economics is in need for thorough reconsideration. Economic phenomena, and more generally social ones, are indeed characterised by a degree of contingency so high that, according to Lawson, "successful event prediction is typically not much more creditable than winning a lottery" (p. 3). Had the crisis been predicted through the application of mathematical models, so Lawson's argument runs, it would have meant little more than a stroke of luck, and would not reduce the urgency of a substantial readjustment of the discipline.

The argument that we should consider central in Lawson's book is perhaps that the contemporary mainstream project is characterised by a continuing practice of ontological neglect. The latter is a concept previously employed by Lawson (2003; 2007), and further developed in his last effort, based on the idea that the application of mathematical techniques to the study of social phenomena is inappropriate. Given such incompatibility, mainstream economics' persistence in universally applying only formalistic models to the study of all types of phenomena implies that the former neglects the nature of social phenomena themselves (i.e., their ontology). A major part of the book deals with the nature and historical origins of this neglect, the causes of its perpetuation, and its consequences-all of which I will now attempt to summarise.

Why does the application of mathematical formalism within economics imply the neglect of social ontology? Why are the two incompatible? Lawson's answer to these questions, which provides an explanation to the fact that modern economics has "continually failed on its own terms" (p. 112), rests on the fact that stable correlations between economic variables have not and cannot succeed. This essentially means that social phenomena are not characterised by the kind of regularities that a) populate natural phenomena and b) can be captured by mathematical techniques. Mathematical deductivism of the kind that is universally employed within mainstream economics, in fact, works well in contexts where closures, i.e., systems in which event regularities occur, are ubiquitous. Instead, since social phenomena originate from the relational interaction of their constitutive elements, social reality is in a constantly changing condition of transformation, thus making closures-especially of causal sequence-extremely rare. Closures of causal sequence are "systems in which the events correlated 
are such that one set [...] [is] considered to stand in the causal history of the remaining events" (p. 38), and imply a conception of social reality as composed by isolated atoms exercising their own invariable and independent effects. This atomistic conception of social reality is precisely what Lawson interprets as ontological neglect.

Lawson further develops his argument on the ontological neglect, warning against the undisciplined use of assumptions. In his view, any deductive exercise that knowingly rests on false premises is meaningless because "so long as that analysis includes assumptions that are known to be false of this, and any really possible, world the analysis itself gives no added credibility to any conclusion drawn" (p. 114). Not only similar analyses are not capable of validating any given hypothesis, but as long as false premises are allowed in deductive exercises, alternative premises could be used precisely to disprove the same hypothesis, hence emptying the exercise of any scientific validity.

An important element in Lawson's book is his attempt to venture outside the borders of economics and the philosophy of science as they are academically conceived and engage in a meta-academic analysis. In doing so he provides an original account of the historical and causal origins of the difficulties faced by modern economics that I believe is helpful to understand where the discipline is going. According to Lawson, as previously mentioned, the crisis of modern economics is not a recent event, but rather one whose origins date back to the success that mathematical techniques brought to the natural sciences (most importantly physics) in the first half of the 20th century. It is also a crisis that is caused by the gravitational pull towards a single ideology: not an economic ideology oriented towards a specific political stance, but rather a methodological ideology based on the "doctrine that all serious economics must take the form of mathematical modelling" ( $p$. 152). Started as a fascination for a type of formalism that rapidly turned into an article of faith for large parts of western society, the process of mathematisation has indeed become a self-reinforcing mechanism that has radically altered the way in which economics is taught and studied in and outside the academy. Lawson interestingly observes that:

Many economists use mathematical deductivist methods just because this is what is required of them, not because of any deep belief in their relevance or utility. [...] Those with power allow almost no leeway for the undertaking of alternative approaches to 
formalistic modelling [and] act as very restrictive gate keepers (p. 139).

Another crucial reason for the dominance of mathematical formalism in mainstream economics, Lawson argues, is precisely its enduring failure to demonstrate anything really new, and hence its inability to seriously challenge the status quo. While the mathematisation of the discipline has in fact led economists to believe in their capacity to predict social phenomena, thus turning economics into a collection of forecasting exercises, its recurrent lack of tangible successes has rendered it politically harmless and can explain how it came to dominate. Indeed, while other economic approaches have traditionally targeted the incoherencies and injustices perpetuated by the leading sources of power, the methods applied by mainstream economists have systematically failed to similarly confront the state of affairs. This has in turn rendered mainstream economists less threatening: we can therefore assume that it has led mathematical formalism to find supporters within economic and political authorities, thus overshadowing other methodologies.

Among the many interesting contributions collected in Lawson's book, perhaps one of the most prominent is his 2013 Cambridge Journal of Economics article entitled "What is this 'school' called neoclassical economics?". In this piece, featured as the fourth chapter of the book, Lawson attempts to clarify some of the confusion surrounding the use of a common term in the debate on modern economics, i.e., the adjective 'neoclassical'. From a purely taxonomical point of view, Lawson argues in favour of

[...] an interpretation that is consistent with the historical origins of the meaning of the term given it by Veblen; is both continuous with, as well as different from, a meaningful conception of classical economics; [...] encompasses seemingly all the explicit modern interpretations [...]; possesses a clear referent, one that is currently without a category name; and is useful in at least (through all the foregoing) bringing clarity to academic discussion (p. 60).

More substantially, he advances the idea that since all subdisciplines within economics are identifiable according to their methodological stance rather than their focus on a particular object of analysis, neoclassical economics too is characterised by a specific 
methodological architecture. In particular, it is "a version of deductivism that posits functional relations presupposing closures of causal sequence" (p. 38). Lawson also argues that such interpretation is somehow complementary to Veblen's original intuition that the neoclassical approach recognises the causal-processual nature of social phenomena, but fails to determine methods that are appropriate to address it. Lawson's theory of ontological neglect is therefore not merely compatible with Veblen's interpretation of neoclassical economics, but rather an evolution inspired and derived from it.

One of the major contributions of Lawson's book is the clarification of the division between the heterodox and neoclassical traditions in economics. In particular, the former is identified with the rejection of the latter's methodological stance: the heterodoxy is such because it is open to a plurality of approaches that are instead rejected a priori by the neoclassical reductionism. Equilibrium analysis is an example of such methodological divide. In the neoclassical camp equilibrium analysis represents the search for a solution to a mathematical problem which is considered the true representation of reality (and is therefore necessary to presuppose the discipline's usefulness). The heterodoxy, instead, tends to favour an interpretation of equilibrium as balance or social order, thus reflecting its tendency towards social illumination rather than formalistic modelling (p. 184). Although the equilibrium example proves that the two approaches have radically different ontological presuppositions, the ontology of heterodox economics has never been explicitly explored by its proponents as it should have. Indeed, just like mainstream economists, heterodox ones also have tended to overlook any systematic analysis of the conception of reality on which their methodological plurality rests, and which, according to Lawson, is the essence of their superiority.

Plurality is a recurring theme in the book. Its centrality hinges upon Lawson's interpretation of academic economics as a discipline polarised precisely along the degree of methodological pluralism allowed by its contributors. Despite his strong support of more pluralistic approaches to economics, Lawson has not been immune to critiques, some of which have come from other advocates of what are broadly interpreted as heterodox approaches. Three of the most important ones appear in the tenth chapter of the book, where the author engages in a debate with them. Davis (2006), Garnett (2006), and Van Bouwel (2005) present three different arguments advancing the idea that Lawson's excessively 
inflexible attitude is causing damage to his own agenda. Albeit different in the content of their critiques (Davis looks at the strategic interaction between mainstream economics and the heterodoxy, while Garnett and Van Bouwel tackle the risk of generating a new orthodoxy with different superficial traits but similar monolithic stance), all three authors point their fingers at the intransigent style that Lawson applies to his assessment of neoclassical economics. In response to these (tenuous) accusations, Lawson elaborates his position in the direction of what he terms an "ontologically bold but epistemologically and substantively very cautious" (p. 213) position. Indeed, Lawson concludes that within his conception of good economics there is room for different types of research practices, including mathematical formalisms-a discipline in which he has been trained (Lawson 2009) - but not for the "dogmatic insistence that only these sorts of methods be used, irrespective of their ability to illuminate" (p. 210). Moreover, from his comment to some of his critics and other recent contributions in the broad heterodox methodology galaxy (including most notably Colander et al. 2009 and Soros 2009), emerges the idea that Lawson's stance is not in opposition to mainstream economics per se, but rather a specific mainstream, i.e., the modern and contemporary one.

As anticipated, Lawson's book constitutes an important and welcome contribution to the literature on economic methodology and the academic discipline as a whole. One of its merits is the uncompromising position that it takes in a debate where one faction (the one supported by Lawson himself) is under-represented in numerical terms and enjoys limited political and institutional power. Some of the central topics of The nature and state of modern economics are not new. Thorstein Veblen initially touched upon them more than a century ago and they were later picked up by the economic heterodoxy-including Lawson, whose 2003 book Reorienting economics was already targeting similar issues. Nevertheless, I believe that the events and conditions that brought about the global financial crisis and the debate, both public and academic, that the latter has sparked on the role of economics justify a similar effort and its timely publication. Lawson offers alternative interpretations for understanding some peculiarities of the relationship between economics and the phenomena that it aims to analyse, and, in doing so, provides the reader with a map and compass to navigate through the academic debate on these issues. About half of the chapters come from articles published before 2010, 
which begs the question whether the book is still relevant today. I believe it is, thanks to its balance between historical and methodological analyses, and because the bulk of Lawson's arguments concerns tendencies that are still observable today.

In my opinion the major weakness of the book is the lack of connection between the theory on the leading methodological ideology behind modern economics presented by Lawson and the inevitable influence that political institutions have on academic ones. The power that political institutions tend to exert on the major centres of knowledge production (including universities) in our times is undeniable, and the fact that "most academic economists have little idea what neo-liberalism even means" (p. 4) can hardly immunise them from its influence. Although Lawson rightfully recognises the role played by neoclassical economics' predictive failures in explaining its ties with political and economic authorities, I believe that his analysis would benefit from a deeper consideration of this element. Another, perhaps minor, flaw of The nature and state of modern economics concerns Lawson's style of writing, which, albeit unquestionably pleasant and suitable for the academic readership, is characterised by frequent use of long and elaborate footnotes. Although there is nothing wrong with such habit per se and fits well with journal articles and similar types of publications, when transposed in books it tends to make the reading flow intermittent by forcing the reader to go back and forth from any given section to the chapter's end, where the footnotes are placed.

Despite these faults, Lawson's book is a precious instrument in the hands of contemporary and future generations of economists to free themselves from an unconscious ideological-methodological preconception. The book is sufficiently accessible to those who encounter for the first time topics in the field of the philosophy of science, but it also delves into the very depth of its arguments in a way that will challenge more knowledgeable audiences, ultimately sparking new debates thanks to Lawson's rigorous and resolute approach.

\section{REFERENCES}

Colander, David, Hans Föllmer, Armin Hass, Michael Goldberg, Katarina Juselius, Alan Kirman, Thomus Lux, and Brigitte Sloth. 2009. The financial crisis and the systemic failure of academic economics. http://keenomics.s3.amazonaws.com/debtdeflation_media/papers/Dahlem_Repor t_EconCrisis021809.pdf (accessed February 2016). 
Davis, John B. 2006. The nature of heterodox economics. Post-Autistic Economics Review, 40: 23-30.

Garnett, Robert F. 2006. Paradigm and pluralism in heterodox economics. Review of Political Economy, 18 (4): 521-546

Lawson, Tony. 2003. Reorienting economics. London: Routledge.

Lawson, Tony. 2007. What has realism got to do with it? In The philosophy of economics, ed. Daniel M. Hausman. Cambridge: Cambridge University Press. Chapter 24.

Lawson, Tony. 2009. Cambridge social ontology: an interview with Tony Lawson. Erasmus Journal for Philosophy and Economics, 2 (1): 100-122.

Soros, George. 2009. The crash of 2009 and what it means: the new paradigm for financial markets. New York: Public Affairs.

Van Bouwel, Jeroen. 2005. Towards a framework for pluralism in economics. PostAutistic Economics Review, 30, article 3.

Marco Sebastianelli is a $\mathrm{PhD}$ student at the Institute for Advanced Studies of Pavia. His research focuses on possible conceptualisations of human well-being based on the role of rationality within the capability approach.

Contact e-mail: <marco.sebastianelli@iusspavia.it> 